\title{
Proper care for the dying: a critical public issue
}

\author{
Kenneth R Crispell and Carlos F Gomez University of Virginia and University of Chicago, respectively
}

\section{Authors' abstract}

The ability of the medical profession to sustain life, or more appropriately, to prolong dying, in patients with terminal illness, creates a most complex and controversial situation for all involved: the patient, if mentally alert; the patient's family; and the medical care team including physicians, nurses and attendants. This situation is especially complex in large acute care hospitals where medical and nursing students, residents and house officers receive advanced medical training.

A major problem, prolonging the dying of the terminally ill, with its medical, legal, ethical and economic complexities now confronts American society. The problem is particularly acute in teaching hospitals, in which one finds a disproportionate number of terminally ill patients.

The ability to work at these questions as a community rather than as adversaries will determine much about the ability of the health care system to respect the dignity and autonomy of those who seek aid and comfort when faced with serious illness and impending death. Better communication between the physicians, health care providers, the lawyers and ethicists must be developed in order to solve these problems.

Over the next ten years society and our elected representatives will be making very demanding decisions about the use of the health dollar. One possible way to prevent increasing costs is to reach significant agreement on the proper care of the dying.

Proper care for the dying is being considered, discussed, and evaluated by very thoughtful people. It is not governments which should decide who is to live or who is to die. There is the serious problem of the 'slippery slope' to euthanasia by omission if cost containment becomes the major force in formulating policy on the proper care of the dying.

Americans find themselves facing new and uncomfortable life and death decisions where patient choice, costs of care, quality of life, and perceived liability have to be taken into account; all of which results in much confusion. Citizens fear they will lose control over decisions affecting their own lives should

\section{Key words}

Terminal care. they become debilitated and seek aid in the health care system. Providers of health care increasingly fear litigation from disgruntled patients and their families. Third party payers feel pressure from their constituents to stem the flow of resources to high-tech interventions which merely prolong dying. Having entered into new zones of human freedom, providers and users of health care must learn how to communicate about death, how best to care for the dying, how to use available legal support for autonomy, and how to update the legal system to deal better with this new reality.

The ability to work at these questions as a community rather than as adversaries will determine much about the ability of the health care system to respect the dignity and autonomy of those who seek aid and comfort when faced with serious illness and impending death. Better communication between the physicians, health care providers, the lawyers and ethicists must be developed in order to solve these problems.

A major problem, prolonging the dying of the terminally ill, with its medical, legal, ethical and economic complexities now confronts American society. The problem is particularly acute in teaching hospitals, in which one finds a disproportionate number of terminally ill patients.

'Terminally ill' is defined as a state of disease characterised by progressive, irreversible deterioration, with impairment of function and survival limited in time. The advent of modern technology, new therapeutic agents and equipment, as well as sophisticated nursing care allow health professionals to become expert in saving and prolonging life. Most professionals, steeped in the Hippocratic tradition of saving lives, are unable and unwilling to allow or assist a terminally ill patient to die.

The ability of the medical profession to sustain life, or more appropriately, to prolong dying, in patients with terminal illness, creates a most complex and controversial situation for all involved: the patient, if mentally alert; the patient's family; and the medical care team including physicians, nurses and attendants. This situation is especially complex in large acute-care hospitals where medical and nursing students, 
residents and house officers receive advanced medical training.

Two case histories may serve to illustrate this extremely serious problem which faces numbers of patients, their families, their physicians, and health care providers in this country.

$\mathrm{Mr}$ W S, an 83-year-old man, was admitted to a large university tertiary-care hospital in a semicomatose condition, having been brought to the emergency room by his family who could no longer 'care for him at home'.

Seven years previously, the diagnosis of multiple myeloma, a rather rare form of cancer, had been made. Over the next seven years, the patient received all known treatment for this condition, with minimal response. Bone pain, common in this disease, was relieved but the progression of the illness was unaffected. The family was informed that no further treatment would be helpful and that he should be made as comfortable as possible during his last days. They preferred, as did the patient, that he be cared for at home rather than in a nursing home.

When this patient was admitted to the hospital, resident physicians ascertained that he now had severe kidney failure, a known complication of this type of cancer. This explained his semi-comatose and confused condition. Residents immediately started the known and well accepted treatment for kidney failure, dialysis. This procedure is expensive, prolonged and uncomfortable, and carried out daily for the first few days. The patient became somewhat less confused after the second day of treatment, but complained of the discomfort of the dialysis.

The senior physician primarily responsible for the patient's care, after consulting with the family and with their concurrence, ordered the dialysis discontinued. There was agreement to make the patient as comfortable as possible and to let him die in peace. Without dialysis he became comatose and died within a five-day period. The total period of hospitalisaton was a relatively short seven days.

The second case is that of Dr D J, a 66-year-old physician and confirmed diabetic, who was admitted to a tertiary-care hospital for surgery to repair an aortic aneurysm (a weakness and bulging in the wall of the large blood vessel leading from the heart which, with its branches, supplies all parts of the body). This patient was considerably overweight, a chain smoker, and for some time had exhibited an elevated blood pressure. Three years before admission he had suffered a severe stroke which left him with marked residual paralysis of his left leg and some difficulty in the use of his left arm. Two years before this admission he had undergone surgery to relieve blockage of his carotid arteries, the large blood vessels supplying the brain. This procedure produced little change in his condition. Dr D J was forced to give up his practice and he became severely depressed. Six months before this last admission, physical examination and $\mathrm{x}$-ray studies revealed the aortic aneurysm. This aneurysm is capable of rupturing spontaneously, producing instant death. He was advised to undergo aortic surgery as a preventive measure, and though he knew the hazards of this surgery, he elected to proceed with it.

During surgery he suffered two periods of cardiac arrest and was successfully resuscitated on both occasions, although he was left with some residual brain damage. The operation was technically successful, but the patient remained semi-comatose following the procedure. As a result of kidney failure the patient required daily dialysis. On the third postoperative day, he developed severe difficulty in breathing and was placed on a respirator. Severe infection of his lungs required large daily doses of intravenous antibiotics.

Dr D J was seen in consultation by at least seven specialists, all of whom were his friends and his former associates. He was also well known to the nurses in the recovery room.

Over the next four weeks his wife and family visited him daily. His physicians never mentioned the possibility of discontinuing the 'life-saving' procedures but left the family with the impression that recovery was possible. It was only after a medical school classmate and long-time friend presented the patient's wife with the fact that recovery was extremely unlikely that she suggested that 'heroic measures' be ceased. The total period of time in the hospital 'prolonging his dying' was five weeks at a cost of four hundred thousand dollars.

These two case histories represent typical examples of the possibility of prolonging life due to the results of medical research and advancement of new technology. Before the advent of chemotherapy in the 1960 s Mr W S would have lived only one to two years. Dr D J was alive because insulin was available to treat his diabetes. The successful surgical repair of his aorta has been possible only for the past thirty years. Without. the modern methods of resuscitation he would not have survived cardiac arrest.

The most difficult decision facing health care professionals is when and for how long to carry out costly and sophisticated procedures in patients with terminal illness. The proper medical care of the patient with a terminal illness may not necessarily be prolongation of life with every modern technique available, but rather to aid the patient, with the concurrence of the family, to die with dignity and without unnecessary pain and suffering. It might be said that $\mathrm{Mr}$ W S had proper medical care and that Dr D J had excellent technical care, but that both had improper overall medical care.

Many persons, including health professionals, will not agree with the above conclusions regarding the management of these two dying patients. Young physicians caring for $\mathrm{Mr}$ W S expressed quite openly that they considered it improper medical care to discontinue the dialysis. They pointed out that there are no legal restrictions on the use of dialysis and 
occasionally patients with multiple myeloma may respond to chemotherapy, including the renal disease, and may regain kidney function if they can be kept alive long enough to respond to therapy.

A third case provides an example of a patient choosing his own treatment of his terminal illness. Dr B J, a 73-year-old emeritus professor of medicine, died in the peace and quiet of his home in the presence of his family.

Approximately eight years before his death he was found to have a tumour of his right eye. A biopsy revealed that the tumour was a melanoma, a highly malignant cancer. After consultation with associates in ophthalmology and cancer therapy, he chose radiation therapy rather than removal of the eye. $\mathrm{He}$ had reviewed the literature and even though removal of the eye had a slightly higher cure rate, he wished to retain bilateral vision as long as possible.

He did very well for the next seven years except for the expected development of a cataract four years after radiation. This was surgically removed and he continued in relative good health. He was an avid horseman and continued to enjoy his favourite sport. $\mathrm{He}$ also continued to work part-time as a consultant on the medical service. One year before death he developed diabetes and was placed on oral hypoglycaemic agents. Six months later he became jaundiced, one of the known complications of these drugs. However, physical examination revealed an enlarged liver. The drugs were stopped but the jaundice continued. With a great deal of urging by his colleagues he submitted to liver biopsy. The biopsy revealed metastases which were easily identified as originating from the melanoma.

Again with the urging of his colleagues he agreed to start a course of chemotherapy, on condition that it was carried out on an outpatient basis. The therapy, as expected, caused nausea, vomiting, and malaise. He then told his physician that he did not want to continue therapy. He preferred to be at home with his family. One month before death he enjoyed a few days teaching his young grandson how to ride. He gradually became weaker and spent his last few days in bed attended by his wife with an occasional visit from close friends. His children, including grandchildren, were with him for the last forty-eight hours.

This physician, with the full concurrence of his family, chose to die at home rather than in the isolation of a room in a hospital.

It should be pointed out that this was a wellinformed 'medical family': the wife was a nurse, one son was a physician, one daughter was a nurse and her husband was a physician. It is possible that many individuals would choose this way to die if they could become as well informed as this medical family.

In presenting these cases we are really discussing two sorts of problems: economic moral questions (resource allocation), and non-economic moral questions (human dignity and quality of life).
A discussion of economic moral issues will be political, the government being the principal provider of the health dollar. It must be emphatically emphasised that governments should not decide who lives or dies. One republic in the 1930s made this decision and it eventually led to the destruction of over six million lives. Malcolm Muggeridge in a recent interview stated: 'I'm not exactly in favour of prolonging life in this world but I am very strongly in favour of not arbitrarily deciding to end it' (1). He points out that the Weimar Republic was the first government in modern times to pass euthanasia legislation. This legislation provided the basis, first of all, for getting rid of what were called useless or nonproductive lives: the sick, senile, or mentally afflicted. Later this included defective children and people who were not considered to be appropriate citizens of the State. To us, one of the most distressing aspects of this tragedy was that physicians carried out the government's decree and that the medical profession subsequently continued to co-operate with the Nazi authorities in putting it into effect.

At present, there are no hard and fast rules for the physician, family or patient in dealing with the very complex non-economic moral issue - quality of life and/or death with dignity.

History tells us that over the years attitudes towards death have changed. Phillippe Aries points out that:

'In the beginning, man apparently did not fear death. Death was accepted without fear, as being part of the natural progression of life. Death was neither hastened nor delayed. This situation existed for a millennium. Dying was a public event and death took place in the presence of family, friends, neighbours, and children.

At the turn of the century, two-thirds of people who died in this country were under the age of 50 , and most died at home in their beds surrounded by their family and friends. Children learned to view death as a part of life, not threatening or unusual, but simply a part of reality. Today most deaths occur in an older population, those over 65 years of age, and two-thirds of our people die in medical institutions and nursing homes. Most children are not exposed to death in their formative years when they have the security and comfort of their family to help them deal with it. That they may have difficulty coping with death when they become adults is not surprising' (2).

What happens to most patients with a terminal illness in a university teaching hospital setting? To begin with, a majority of patients are referred by their personal physicians. Many come from a considerable distance, and may or may not be accompanied by their families. In many instances, the family returns home after the patient has been admitted. Many university hospitals are the hospital of 'last resort'. Even though the history, physical examination, and letter or telephone call from the referring physician suggests a 
terminal illness, resident physicians feel compelled to order a whole new battery of technological procedures and laboratory tests. As teachers we have taught students to be thorough in the detection of disease, and to aid the patient to live rather than aiding him or her to die. Is the system wrong? Not basically, but it does present serious problems in the care of the terminally ill patient. This is especially true if relief of pain and suffering is not given equal or even more consideration than the costly and sometimes painful search for the ultimate diagnosis and treatment. What is needed is sound professional judgement as to what should be done to and for the patient.

However, in order to establish a sound basis for this professional judgement the medical profession will need help and advice. Fortunately, there are now in America several organisations whose main function is to educate the public about the problem of prolonging dying, one of the most active being Concern for the Dying. This organisation has been particularly effective in alerting the public to the concept of the living will, a document which allows a person to state that no life-sustaining mechanisms are to be used to prolong life in cases where there is no hope for recovery. Many States have adopted such provisions, making them acceptable legal documents. At a 1983 national meeting on the living will, sponsored by Concern for the Dying, Alexander Capron, Professor of Law at Georgetown University, noted four fundamental facts demanding solutions creatively adapted to local and institutional circumstances: 1) death is no longer a natural process; 2) death occurs in institutions; 3 ) death is not an unexpected event for most people (ie at least half the population dies from illness diagnosed more than two years beforehand), and 4) this society remains very ambivalent in its reaction to death.

Capron maintained that 'health care professionals and institutions serve patients best by maintaining a presumption in favour of sustaining life while recognising that patients are entitled to choose to forego any treatment.

'Above all', he stressed, 'the voluntary choice of a competent and informed patient should determine whether or not life-sustaining treatment is continued or discontinued. The corollary is that institutions and professionals should do all they can to enhance the patient's ability to make such competent and informed choices' (3).

Many organisations of physicians have been addressing the important issue of the proper care of the terminally ill, the American College of Physicians being among the most active. Recently the New Jersey chapter of this group issued some guidelines for the care of the hopelessly ill patient. Some of the details of the guidelines may certainly serve as a basis for future debate. They are as follows:

'The physician's responsibility: All medical codes recognise that the physician's duty is to act in the best interests of his/her patients, to relieve suffering and improve health while maintaining competent and compassionate service with respect for human dignity.

Moral concerns: Dignity is hard to define and the perception of indignity clearly depends upon the observed and the observer. However, there are circumstances in which the relentless maintenance of medical treatment is inconsistent with what is perceived to be the patient's dignity.

Life itself is of value even in the case of patients hopelessly ill with incurable disease. When doubts exist, a presumption should be made in favour of life preservation. The legal and moral prescription in favour of life always should be recognised, but the principle is not absolute. Honest and responsible people may differ in gradations of valuation and consider quality of life in addition to quantity. Societal attitudes increasingly recognise a competent patient's right to decline treatment even if in so doing death may be hastened. Admittedly, this is not uniformly accepted. Differences also must be reconciled in order to permit formulation of reasonable and compassionate treatment plans.

The further the patient is from expected death, the greater the necessity to consider how much life itself has become burdensome to the patient, rather than whether the patient is a burden upon family or society. Devaluing life on the basis of advanced age alone, non-productivity, cost, or lesser degrees of disability is unacceptable' (4).

As might be expected, not all physicians agreed with the guidelines. For example, here are two rather divergent views. One physician states:

'It should be stressed that treatment that prolongs pain and suffering by patients and relatives and only prolongs the physiologic process of dying benefits no one, least of all the patient' (4).

\section{Another states:}

'Perhaps philosophers and theologians can resolve $N$ these perplexing problems, but the medical profession must follow a one-track course favouring life with a humane and sensible therapeutic approach' (4).

Some organised religions are also becoming involved $\stackrel{\mathscr{\complement}}{\rightarrow}$ in this issue. The following is typical of such 70 involvements:

'It was moved that the Eleventh Biennial Convention of the Lutheran Church in America direct the implementation of the social statement Death and Dying, as follows:

I. Congregations:

A. Provide an educational programme that includes 
sessions on death and dying, so as to encourage members to reflect about these issues within a Christian context;

B. Sponsor training sessions to help members learn how to minister to the chronically ill and to those in death-and-dying situations and to members of their families;

C. Encouragement and development of mutual support groups within the congregation.

D. Join with other congregations and community groups to establish and maintain supportive care programmes, including hospice care' (5).

Several State agencies such as the Oregon Health Council have held a series of public hearings and have made the following recommendations:

'1. That the Oregon Health Council request the Oregon Association of Hospitals, the Oregon Medical Association, the Oregon Nurses Association and appropriate health professional, religious and patient advocate organisations to encourage the formation in health care institutions throughout the State of Bioethics Committees containing community members. That the Oregon Health Council encourage the Oregon Association of Hospitals to conduct a study on the experience in Oregon of such Bioethics Committees.

2. That the Oregon Health Council and the Health Systems Agencies request Oregon's religious organisations and community service organisations to develop educational and service programmes to improve the social and spiritual support available to the terminally ill and their families' (6).

At the federal level a report by the President's Commission for the Study of Ethical Problems in Medicine and Bio-Medical and Behavioural Research includes one volume pertaining to Deciding to Forego Life-sustaining Procedures (7).

It is encouraging that so many private and public groups are continuing to address the problems of health care. Many have emphasised the problem of the proper care for the dying. There is an urgency for a solution to this problem, even in a nation as wealthy as the United States, because rising costs of medical care in America have reached an alarming level. The Social Security System, which includes Medicare, is in serious financial trouble, due in no small part to our inability to control rising costs of Medicare. The medical profession has been slow to respond to rising costs and the federal government, in an attempt to halt these increasing costs, has stepped in with new regulations. Stricter regulations can be expected if those presently in effect prove ineffective.

Prolonging dying in hospitals, Medicare and cost containment are very much interrelated for the following reasons: 1) We have an aging population which by the year 2000 will represent over 20 per cent of our population; 2) Eighty per cent of the health dollar is consumed by 13 per cent of the population of which half of the patients are over 65 and on Medicare; 3) The single most expensive medical bill is for the last week of life of a patient terminally ill in an acute care hospital; 4) Twenty-two per cent of the Medicare budget in 1983 was for the cost of hospital care for the last year of life, and 5) Eighty per cent of our population now dies in institutions.

Over the next ten years society and our elected representatives will be making very demanding decisions about the use of the health dollar. One possible way to prevent increasing costs is to reach significant agreement on the proper care of the dying.

One of the costs which will surely be evaluated is the cost of terminal care for a dying patient in a hospital setting. To re-emphasise, the single most expensive medical bill at this time in America is for the last week of life in an acute care hospital. If we decrease the dollars spent for hospitalisation for the last year of life, might these savings be more properly allocated to other health programmes which would be more beneficial to all of society? In that the federal tax dollar supplies over fifty per cent of the funds spent for health care, the total amount and the allocation becomes a political issue.

The distinction between non-economic and economic concerns must be made even more specific. If we had unlimited funds for measures which prolong death, should we use them? This will be the major economic-moral question to be answered if economic constraints prevent 'proper care of the dying'. The slogan 'death with dignity' emerged when overtreatment of patients became a threat. Will economic constraints bring the threat of under-treatment of patients? It is obvious that the problem we face is the formation of some non-governmental guidelines on what constitutes 'proper care'.

Whether properly formulated guidelines for the proper care of dying will really reduce the cost of medical care is unknown. Our thesis is that at the present time there is 'over-treatment' and 'overhospitalisation' of the dying patient. This thesis needs to be very carefully evaluated by working out proper guidelines and proposing alternate methods of care which will be cost-saving and humane. Hospices and visiting nurses who provide home health care, which have been so successful in Great Britain, have been less popular in America. These two methods of care need to be evaluated in more depth in America as a humane alternative to hospitalisation.

Proper care for the dying is being considered, discussed, and evaluated by very thoughtful people. It is not governments which should decide who is to live or who is to die. There is the serious problem of the 'slippery slope' to euthanasia by omission if cost containment becomes the major force in formulating policy on the proper care of the dying.

More information from relatives and friends of deceased patients as to whether or not in their opinion the dying patient did receive proper care is desperately 
needed. Such studies are being instituted in order to gain sound information which will help formulate proper guidelines for terminal care. At present, without sound data, there are no universal concrete plans but the following issues should be considered.

1. To quote Capron again: 'Above all the voluntary choice of a competent and informed patient should determine whether or not life-sustaining treatment should be continued or discontinued. The corollary is that institutions and professionals should do all they can to enhance the patient's ability to make such competent and informed choices' (3).

2. For the mentally incompetent patient, each illness must be considered on an individual basis. The decision to withhold therapy should be made by the medical care team headed by the patient's physician in consultation with the patient and his family.

3. Medical care teams in the university teaching hospital are composed of numerous individuals who have direct contact with the patient. All need to be involved as much as possible in decisions concerning terminally ill patients. In our system in acute care hospitals the nurse, resident, medical student and often the orderly spend much more time with the patient than the physician. Failure to include them in decision-making is bad for the patient as well as the physician's own peace of mind. In a recent case in California it was a nurse who instigated murder charges against two physicians who had ordered the discontinuance of intravenous fluids in a postoperative comatose patient. The physicians were acquitted but it is quite possible that the emotional trauma and legal costs could have been avoided if all members of the care team had been involved in the decision to withhold fluids.

4. Full discussion with the patient (if competent) and the family in any case is particularly important. The concept of relieving pain and suffering should be policy rather than hope for any remotely possible cure. The resident and the nurses should be included in these discussions. Our opinion is that this onerous task should not be the sole responsibility of the resident physician unless he or she feels that he can and wishes to handle this by himself. It is not fair or right for the physician to ask the patient and/or the family to take the sole responsibility for the decision. Their rights to do so should be respected but decisions on the course of management can produce serious problems of guilt. On the other hand, families should not feel they have no role in the decisions. Physicians should avoid taking on a strong paternalistic role.

5. At this time it is very difficult to define the role of the bioethicist in our present medical-care system. They are not the primary decision-makers but are of tremendous aid in clarifying values, balancing choices and in arriving at tough medical decisions involving ethical issues. It is of tremendous help to have them as colleagues in discussing the broad spectrum of ethical issues involved in making decisions regarding dying patients. They are most effective if they can visit the patient with the physician, have some firsthand knowledge of the medical-care system, and have a genuine interest in being a participant and not just an outside observer. In a mutual learning process physicians learn something more of bioethics and the ethicists learn about the complexity of a medical-care system in an acute care hospital.

6. The public should be made more aware of the concept of the living will. The physician, if he believes in the concept, is in a position to discuss the concept with patients and their families. It should be noted that most Natural Death Acts, which have been passed in many States, address the physician's responsibility to act on the patient's advance directive and conclude that the physician only has a responsibility to make a good faith effort to transfer the patient if he or she does not wish to honour the patient's advance directive. The statutes do not usually address the question of the physician's responsibility to inform the patient of the availability of the living will mechanism. It might be argued that the physician has a moral duty to disclose the availability of the mechanism even if he or she would not act on it.

William May, a renowned bioethicist, in his book The Physicians' Covenant presents a somewhat different view from that which we have expressed in clarifying values and balancing choices involved in difficult medical decisions. He states:

'It assumes that the practitioner is riddled with uncertainty in facing a particular decision and seeks help from the ethicist in identifying the right set of principles to resolve the quandary. (Some ethicists and clinicians have so honoured this view of medical ethics that they wanted to publish a book on the subject that would fit into the physician's hip pocket for the handy resolution of quandaries.) Images do not function quite so successfully in those situations which the moralists call hard cases. They do not operate as a manual for getting the decision-maker out of an exceptional moral bind in which he or she does not know what to do. Rather, they provide a comprehensive ordering of life - an interpretation of role, metaphysical setting, and institutional context - that makes moral behaviour seem more like a rite repeated than a puzzle solved. An image provides a compelling picture of the world and one's role in it. What one does appears to be what the world compels. The image renders another kind of behaviour unthinkable' (8).

One interpretation of this statement by our colleague in bioethics, James Childress, is that May is calling into question the whole emphasis on 'tough medical 
decisions' or what he calls 'quandaries' or 'dilemmas' in order to emphasise the way images held by professionals order their lives and actions. Hence moral conduct is more a rite than a puzzle, as James Childress has observed (personal communication).

Whether considered a rite or a puzzle, physicians will continue to need help in working out a humane and moral way for the proper care of the dying.

In closing, we will quote from something written to us by one of our distinguished senior colleagues, Eugene Stead.

'The problem of getting out of this world gracefully has not been solved for many of us. How to let people die when their time has come without the rest of us becoming brutalised is still beyond us' (personal communication).

Kenneth $R$ Crispell, MD, University Professor of Law and Medicine, University of Virginia, was formerly Dean of Medicine and Vice President for Health Affairs at Virginia. He now teaches in the Medical School, the Law School, and an undergraduate seminar in 'Moral Choices in Public Policy Decisions'. Carlos Gomez, BS Graduate, University of Virginia, has completed two years of medical school at Virginia. He is now a Pew Foundation Fellow at the University of Chicago studying for his PhD in Philosophy and finishing his $M D$ degree. He will also be taking course work in Public Policy while at Chicago.

\section{References}

(1) Muggeridge M. Modern attitudes toward life and death. Human life review 1979; 53: 99-116.

(2) Friel P B. Death and dying. Annals of internal medicine 97, 5: 721-767.

(3) Capron A. Presented at the National Conference on Living Will, 1983. To be published.

(4) New Jersey Chapter of American College of Physicians. A C P Observer 1984, Apr: 16.

(5) Lutheran Church of the Redeemer. Report of Ninth Meeting, 1982: 257-264.

(6) Oregon Health Council. Final report: Society must decide - ethics and health care choices in Oregon: Oregon Health Decisions. 1985, Jan.

(7) President's Commission for the Study of Ethical Problems in Medicine and Bio-medical and Behavioral Research. Report: Deciding to forego life-sustaining treatment - ethical, medical, and legal issues in treatment decisions, 1983 Mar.

(8) May W F. The physicians' covenant-images of the healer in medical ethics. Philadelphia: Westminster Press, 1983. 